\title{
DIFFERENT APPROACHES IN PERFORMANCE EVALUATION OF WORK ROLLS FOR HOT STEEL ROLLING*
}

Alberto Tremea ${ }^{1}$ Stefano Ricco ${ }^{1}$

\begin{abstract}
In this period a great attention is put on roll cost and the differences in roll behavior in very few situations move the existing balances. Among many variables that are taken into account to evaluate the roll there is the consumption which is normally calculated according to the tonnage rolled. In this work there is a review of some approaches that are used to evaluate the roll efficiency together a description of a new method to make this. The main purpose of this calculation method is to help the comparison of roll results used in different mills. There is the need to have a clear and univocal reference when it's time to think about innovative products. At now there are available roll grades with excellent technological properties but it's necessary to have the right tools for a careful evaluation of roll behavior to take a good decision.
\end{abstract}

Keywords: Hot rolling; Work roll; Roll performance.

1 R\&D Dept. - Innse Cilindri SrI - Via A. Franchi 20, 25127 Brescia, Italy.

* Technical contribution to the 51st Rolling Seminar - Processes, Rolled and Coated Products, October 28th to 31st, 2014, Foz do Iguaçu, PR, Brazil. 


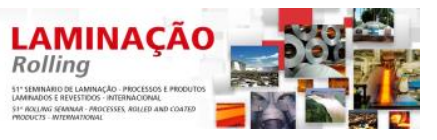

\section{INTRODUCTION}

In the roll bite the situation is critical because there are many phenomena acting together with a variable amplitude depends of the stands in the mill. Solicitations are very hard but the roll has to limit the proper consumption and the abrasion during the campaign. There are situations where the wear of the roll sets the length of campaign but not always. Also the roll surface quality establishes the length of campaign if the abrasion or otherwise the surface damaging exceed a limit that affect the quality of rolled material. The type of surface damaging determine the limit of the campaign length rather than representing a reason to increase the material removal during grinding. The normal situations of surface damaging are resolved by removing $2 \mathrm{~mm}$ maximum for roughing rolls and less than $0,5 \mathrm{~mm}$ for finishing.

For example thermal fatigue has a big effect on roll surface damaging because it produces a network of cracks that weaken the resistance of material but also light phenomena like peeling can give negative effects on rolled material and so also on the setting of campaign length. These types of problems, that affect only the roll skin, tend to reduce the roll performance because of an higher number of grindings not for the level of relative removals. Figure 1 shows a roll surface with peeling and thermal fatigue after a campaign of 2000tons in a F1 stand of a hot strip mill.

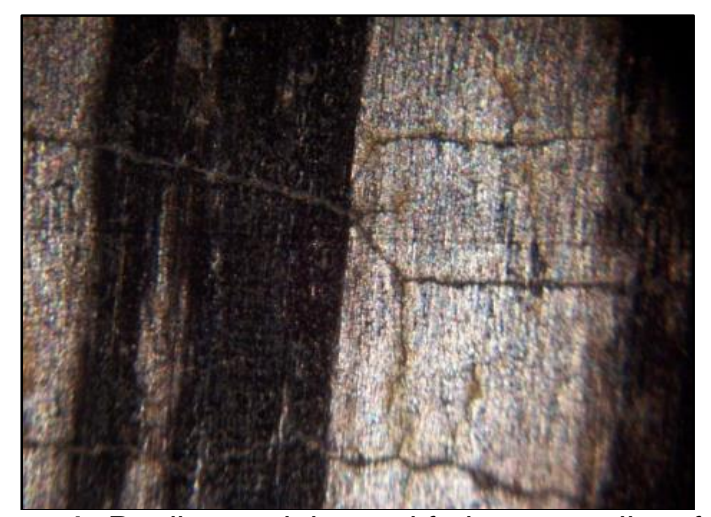

Figure 1: Peeling and thermal fatigue on roll surface

In case of rolling accidents the roll can only limit the damage. Thermal shocks, mechanical overload can produce heavy problems to the roll. The evaluation of these situations, if the relative removals are merged in function of the type of the accidents, becomes very important to characterize the roll behavior as well as the characteristics of the mill in terms of stress level.

The work roll consumption can be split into two parts:

- in the mill during the campaign;

- on grinding machine during the redressing operations.

The first contribution is practically a measure of wear resistance of the roll. This issue can be easily estimates with an analysis of roll surface profile at the end of the campaign. It's common the use of the middle of the barrel like reference section to make this evaluation. Wear is proportional to the length of the campaign but the rolling force and the contact temperature strongly influence its level.

The second contribution is in strictly relation with the damaging of the roll. After normal campaign the effect of damaging on the roll is under $1 \mathrm{~mm}$ on radius.

\footnotetext{
* Technical contribution to the 51st Rolling Seminar - Processes, Rolled and Coated Products, October 28th to 31st, 2014, Foz do Iguaçu, PR, Brazil.
} 


\section{WORK ROLL MATERIALS}

To satisfy the entire requirements of different situations of a mill the work roll materials range over a wide variety of alloys. At now exist a lot of high alloyed materials with a level of carbon starting from $0.5 \%$ up to $3.5 \%$.

In the field of cast irons there are two main classes:

- cast irons with a medium content of alloying elements called Indefinite Chill Iron (ICDP);

- cast irons with a high content of chromium called High Chromium Iron $(\mathrm{HCrl})$.

Steels can be divided in three groups:

- steels with a medium content of alloying elements called Semi High Speed Steel (SemiHSS);

- steels with a high content of chromium called High Chromium Steel ( $\mathrm{HCrS})$;

- steels with a high content of alloying elements called High Speed Steel (HSS).

Table 1 shows the main elements that typify the above mentioned classes of materials for rolls.

Table 1: Typical chemical analysis for work rolls [\%wt.]

\begin{tabular}{|c|c|c|c|c|}
\hline MATERIAL & $\% \mathrm{C}$ & $\% \mathrm{Cr}$ & $\%$ Weq & $\%$ Veq \\
\hline ICDP & 3,2 & 1,5 & $1(\max )$ & 2 (max) \\
\hline HCrl & 2,5 & 15 & $2(\max )$ & $2(\max )$ \\
\hline SemiHSS & 0,8 & 5 & 7 & $1(\max )$ \\
\hline HCrS & 1,4 & 12 & 5 & $1(\max )$ \\
\hline HSS & 1,8 & 5 & 10 & 5 \\
\hline
\end{tabular}

In a mill, these materials work in specific positions:

- ICDP: last finishing stands

- $\quad \mathrm{HCrl}$ : first finishing stands

- $\quad$ SemiHSS: reversing roughing stands

- HCrS: roughing stands

- $\quad$ HSS: roughing stands and first finishing stands

The thermal and mechanical stresses into the roll bite can be considered similar for all stands but the reciprocal level change a lot stand by stand. To analyze in a better way the behavior of a roll it's necessary to separate at least the work conditions between roughing and finishing stands.

A rougher roll comes under a heavy thermal cycle due to high contact time with the slab and consequent cooling so the roll needs to maintain sufficient resistance against wear and cracking to reach the expected rolling program. In this specific application cases of thermal shock can occur also with heavy consequence on the roll; in these situations the damaging is imposed mainly by the heaviness of the problem instead of the properties of roll material. Actually HCrS rolls are the main used rolls but the presence of SHSS and HSS rolls is growing up. Figure 2 gives an idea of damaging for rougher rolls.

* Technical contribution to the 51st Rolling Seminar - Processes, Rolled and Coated Products, October 28th to 31st, 2014, Foz do Iguaçu, PR, Brazil. 


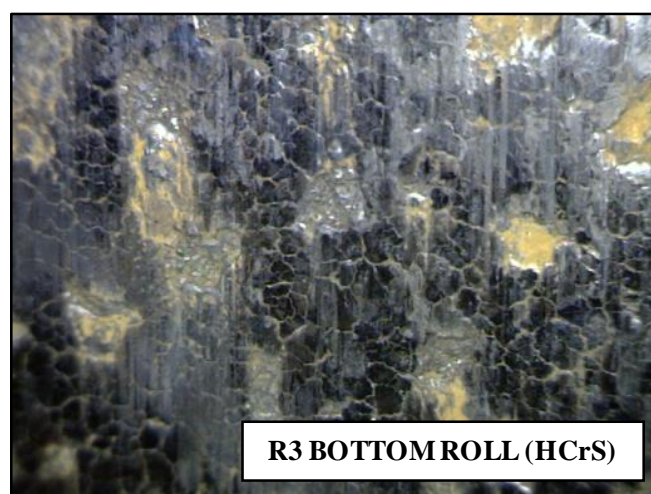

Figure 2: Example of surface damaging in a roll used in a roughing stand

The number of finishing stands can varying from 5 to 7 if we exclude the Steckel mill where normally there is only a single stand. Rolls operating in the first part of finishing group, called normally "Front Stands" or "Early Stands", are subjected to thermal fatigue and a surface damaging due to contact with the strip. In these working position the level of damaging is directly proportional to the reduction made and also to properties of rolled steel. The rolls used in these positions can be $\mathrm{HCrl}$ and/or HSS. Figure 3 outlines an example of roll surface damaging for a roll that has worked in F1 stand.

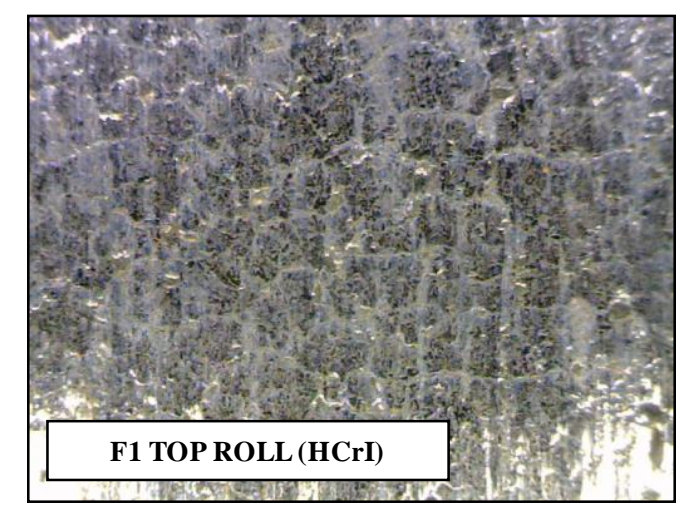

Figure 3: Example of surface damaging in a roll used in a finishing stand (F1)

In the other stands, called "Last Stands" or "Rear Stands", abrasion phenomena are the main cause of roll consumption. Rolls in these position are ICDP. Within this class of material a lot of different solution exist born mainly to improve the wear resistance. The use of new grades of ICDP, called "enhanced", may improve a lot the performance but in many situations the loss of material due to rolling accident covers the real possibility of these rolls.

Table 2 shows the sharing among the class of roll material families operating in respect of the mill type.

\footnotetext{
* Technical contribution to the 51st Rolling Seminar - Processes, Rolled and Coated Products, October 28th to 31st, 2014, Foz do Iguaçu, PR, Brazil.
} 


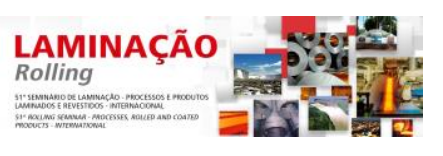

Table 2: Roll materials and applications

\begin{tabular}{|c|c|c|c|c|c|c|c|c|}
\hline MILL & STAND & STEEL & HCrS & SemiHSS & $\mathrm{HCrl}$ & HSS & ICDP & EcICDP \\
\hline \multirow{3}{*}{ 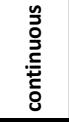 } & Roughing & CS & $50 \%$ & $40 \%$ & & $10 \%$ & & \\
\hline & Finishing FS & CS & & & $90 \%$ & $10 \%$ & & \\
\hline & Finishing LS & $\mathrm{CS}$ & & & & & $30 \%$ & $70 \%$ \\
\hline \multirow{6}{*}{ 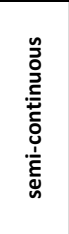 } & \multirow{2}{*}{ Roughing } & $\mathrm{CS}$ & $50 \%$ & $50 \%$ & & & & \\
\hline & & SS & $10 \%$ & & & $90 \%$ & & \\
\hline & \multirow{2}{*}{ Finishing FS } & CS & & & $70 \%$ & $30 \%$ & & \\
\hline & & SS & $10 \%$ & & & $90 \%$ & & \\
\hline & \multirow{2}{*}{ Finishing LS } & $\mathrm{CS}$ & & & & & $20 \%$ & $80 \%$ \\
\hline & & SS & & & & & $10 \%$ & $90 \%$ \\
\hline \multirow{3}{*}{ 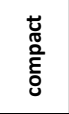 } & Roughing & $\mathrm{CS}$ & $70 \%$ & $10 \%$ & & $20 \%$ & & \\
\hline & Finishing FS & $\mathrm{CS}$ & $10 \%$ & & $60 \%$ & $30 \%$ & & \\
\hline & \begin{tabular}{|l|} 
Finishing $\mathrm{LS}$ \\
\end{tabular} & CS & & & & & $60 \%$ & $40 \%$ \\
\hline \multirow{5}{*}{ 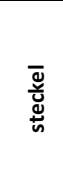 } & \multirow{2}{*}{ Roughing } & $\mathrm{CS}$ & $50 \%$ & & & & $50 \%$ & \\
\hline & & SS & $50 \%$ & & & $40 \%$ & $10 \%$ & \\
\hline & \multirow{2}{*}{ Steckel } & CS & & & & & $70 \%$ & $30 \%$ \\
\hline & & ss & & & & $30 \%$ & $30 \%$ & $40 \%$ \\
\hline & Finishing & SS & & & & & & $100 \%$ \\
\hline
\end{tabular}

\section{PERFORMANCE CALCULATION}

A common way to calculate the roll performance is the comparison between rolled tons and the consumption of roll material in millimetres. Using kilometres of rolled material instead of tons in the calculation gives a chance to make easier an assessment among different mills.

Two indices should be defined in each mill stand by stand:

- "NW" for normal wear $[\mu \mathrm{m} / \mathrm{km}]$;

- "NG" for normal grinding $[\mu \mathrm{m} / \mathrm{km}]$.

A third group of indices should cover all the extra amounts of roll consumption ("ExG"). For example these indices could be calculated like a percentage in respect to the total consumption. To make this possible a codification of the types of roll damaging is required to allocate the relative amounts of extra removals. In this group should compare indices like:

- "ExW" for extra wear, "ExTc" for thermal cracks, "ExM" for marks, ...

Normal working conditions give wear amounts from zero to $2 \mathrm{~mm}$ and grinding amounts can move from $0,2 \mathrm{~mm}$ to $1 \mathrm{~mm}$. To know the kilometres done by the roll is strategical to analyze the results in a good manner. In case of rolling accidents, where thermal shocks or mechanical overload produce heavy losses of roll material, the percentage of extra indices can exceed 50 points while in normal condition these values are under 10 points.

To calculate "NW" is necessary to analyze the wear profiles to evaluate the loss of material together with the kilometres made by the roll. The example in Figure 4 outlines a comparison between wear profile of an EcICDP and a new material now in testing for the last stands. In this case "NW" is around 6,5 $\mu \mathrm{m} / \mathrm{km}$ for classical roll and practically zero for new rolls.

* Technical contribution to the 51st Rolling Seminar - Processes, Rolled and Coated Products, October 28th to 31st, 2014, Foz do Iguaçu, PR, Brazil. 

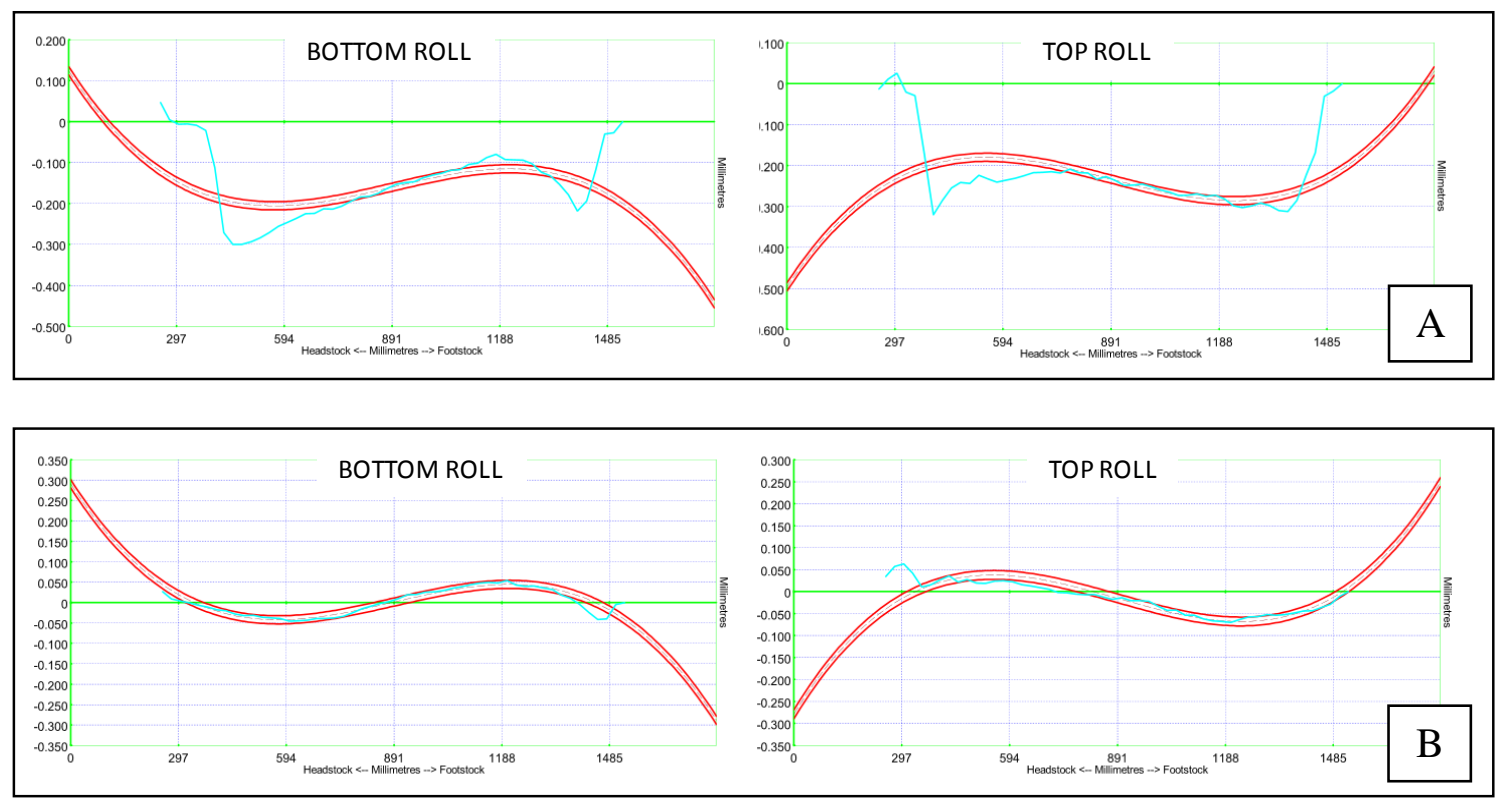

Figure 4 Comparison between roll profiles (A - EcICDP; B - DopICDP)

\section{RESULTS}

In this paragraph there are several examples where the indices described above are used to evaluate the roll performance.

In Figure 5 there is a comparison between two different types of HSS rolls. The parameter "NW" outlines the better wear resistance of high carbon HSS roll quality in respect to the standard type. From this mill information aren't available stand by stand and furthermore no extra grinding amounts are codified. So in this case it's possible only an evaluation on wear resistance.

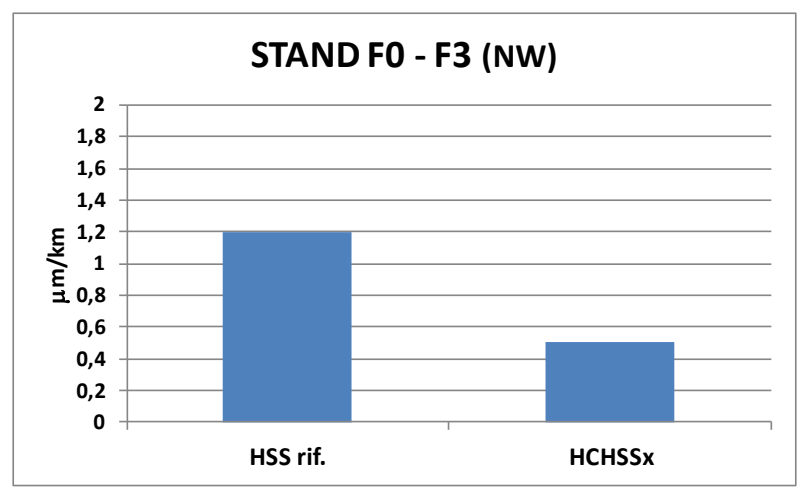

Figure 5: Comparison between HSS rolls in the front stands of a HSM

Another comparison between HSS rolls is in Figure 6. In this HSM the grade B shows a better wear resistance is almost all stands. If we look at the amount of extra redressing ("ExG") the situation is more critical to explain. In this case other information are not available so a further investigation should be made to evaluate for example the "strange" results between stands F1 and F2.

* Technical contribution to the 51st Rolling Seminar - Processes, Rolled and Coated Products, October 28th to 31st, 2014, Foz do Iguaçu, PR, Brazil. 


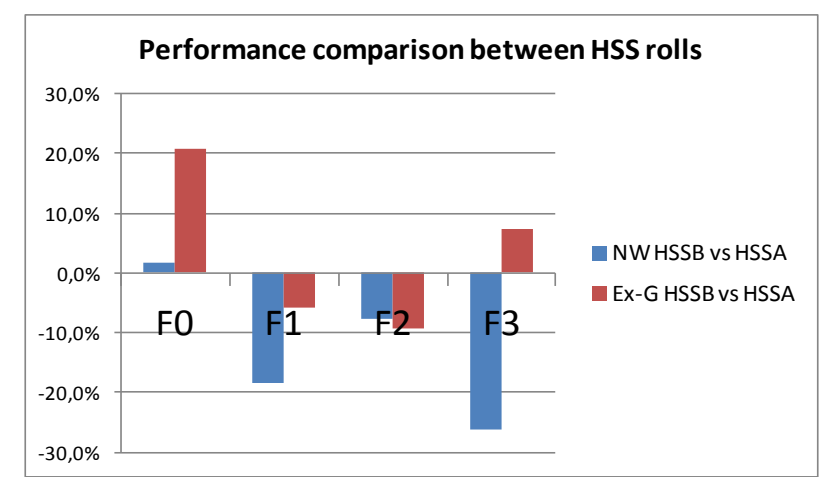

Figure 6: Comparison between HSS rolls stand by stand

If we look at roughing stands Figure 7 confirms the excellent wear resistance of SemiHSS and HSS rolls if compared with HCrS rolls; these results show also that wear is higher in $\mathrm{R} 6$ respect to $\mathrm{R} 4$.

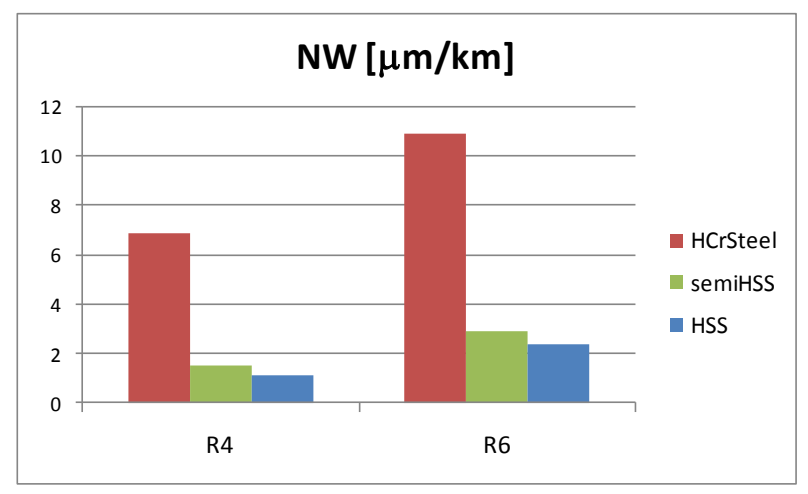

Figure 7: Roll wear resistance in a roughing stands of a continuous HSM

Within the family of SemiHSS rolls the wear resistance can be different among different mills. Noticeable also the hard situation in case of stainless steel rolling (Figure 8).

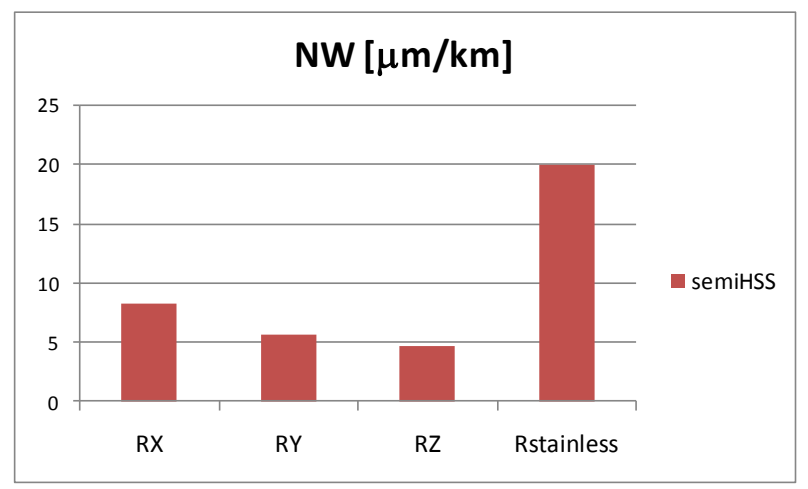

Figure 8: Comparison of SemiHSS rolls in different reversing stand of a HSM

If information are well detailed the evaluation of extra indices can clarify the specific attitudes of different materials within the same class. Figure 9 summarizes a situation for the last stands of a hot strip mill where ICDP rolls are used. EcICDP type $x$ shows the best wear resistance but a lesser resistance against the progress of mechanical cracks (green column in the figure below). ICDP appears very close to the behavior

* Technical contribution to the 51st Rolling Seminar - Processes, Rolled and Coated Products, October 28th to 31st, 2014, Foz do Iguaçu, PR, Brazil. 
of EcICDP type y. This grade shows a good resistance against marks with a wear resistance not so far from EC grades.

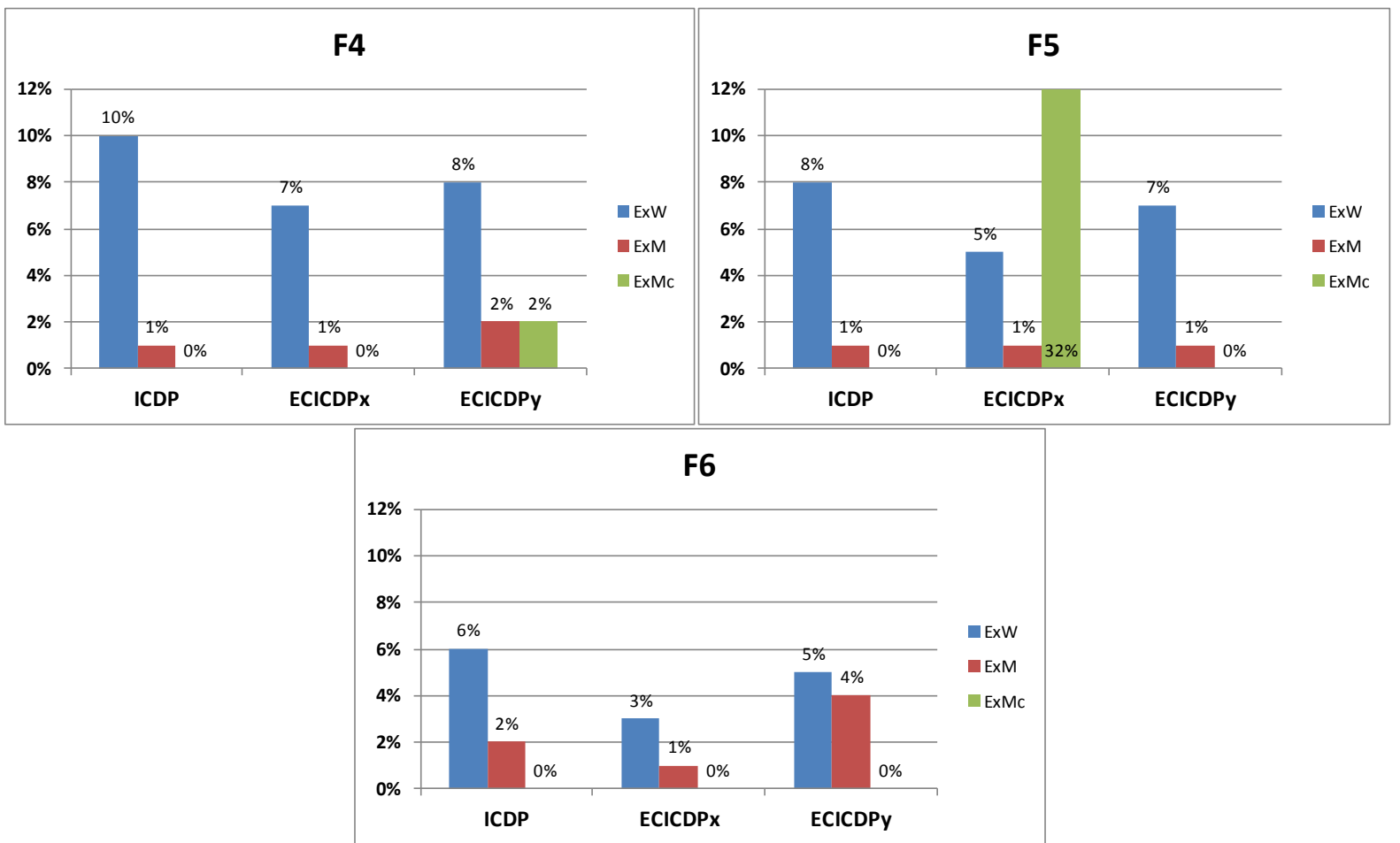

Figure 9: Comparison among extra indices for rolls in the last stands of a HSM

\section{CONCLUSION}

A new approach for evaluation of roll performance was presented. It's a simple way to describe the roll behavior where the main input is the kilometers made by roll together with its loss of material. It is necessary to collect a lot of information, particularly regarding the redressing phase. Also a classification of the amount of redressing material is needed according to the problems on the roll.

To compare the results it isn't enough to discuss about wear resistance but also regarding other degenerative phenomena.

The wear resistance of the same types of rolls can be different also if you compare similar mills. So it's necessary to pay attention in making comparisons among results coming from different mills.

In the case of grinding operations, very often, the situation becomes more critical. Without a proper allocation of the amount of removal material with reference to roll damaging, the validation of effective (or expected) benefits in using a specific roll can be difficult. The indices with the evaluation of extra grinding described in this work should allow a better calculation of roll performance.

\section{Acknowledgements}

Authors thank all technicians for the support and cooperation inside their workshops.

* Technical contribution to the 51st Rolling Seminar - Processes, Rolled and Coated Products, October 28th to 31st, 2014, Foz do Iguaçu, PR, Brazil. 